\title{
Prevalence of Hepatitis B in admitted students of a Private Medical College
}

\author{
Khan $\mathrm{MK}^{1}$, Ahmed KGS ${ }^{2}$, Ansari NP ${ }^{3}$,Jahan $\mathrm{MK}^{4}$
}

\begin{abstract}
Hepatitis B infection is endemic almost throughout the world and is a public health problem. It is a major cause of morbidity and mortality in South East Asian Region. According to literature in Bangladesh the carrier rate is quite high. The present study determines the distribution of the HBV infection by age, sex and social status among medical students admitted into a private medical college. This is a descriptive cross sectional study which is based on a single examination of 1643 medical students who got admitted at one point of Community Based Medical College, Mymensigh in time period from 1995 to 2012. The results of the seroprevalence data evidenced that out of 1643 medical students 05 cases were positive; of which one male and four students belonged to female sex group. The mean age estimated was 17.6 (SD \pm .812$)$ years. The percentage of potential infection among students revealed $0.30 \%$. The study showed that $\mathrm{HBV}$ infection is not very high yet in population of better socioeconomic condition. The present study focused attention on the preventive measures to be undertaken in this country.
\end{abstract}

CBMJ 2012 July: Vol 01 No 02: P: 03-07

Key words: Hepatitis B, seropositive, socioeconomic

\section{Introduction}

Hepatitis B, formerly known as "serum hepatitis", is an acute systemic infection of the liver caused by hepatitis B virus (HBV) and is transmitted usually by parenteral route 1 . Although the infection is endemic almost throughout the world, it is a major cause of morbidity and mortality in South East Asian Region. In earlier days the disease caused epidemics in parts of Asia and Africa and was endemic in China ${ }^{2}$. Its prevalence varies from country to country and is found lowest in countries with high standards of living. About a third of the world population has been infected at one point in their lives including $\mathbf{3 5 0}$ million people who are chronic carriers 3,4 .

The virus is transmitted by exposure to infectious blood or body fluids, such as semen and vaginal fluids, while viral DNA has been detected in the saliva, tears and urine of chronic carriers. Perinatal infection is also a major route of infection in developing countries $^{5}$. Man is the only reservoir of infection which can be spread either from carriers or from cases. The carrier state of HBsAg in hospital staff has been found to be higher than in voluntary blood donor and general population. The incidence of $\mathrm{HBV}$ infection in surgeons is estimated to be 50 times greater than that in general population which is again more than twice than that of other physicians. Other high risk groups for developing HBV infection include personnel working in a health care setting, recipients of blood transfusions and dialysis,

1. Dr. M. Karim Khan*

Professor of Paediatrics, Community Based Medical College Bangladesh, Mymensingh

2. Dr. Kh. Golam Sabbir Ahmed Professor of Microbiology, Community Based Modical Colloge Bangladesh, Mymensigh

3. Dr. Nazma Parvin Ansari, Assistant Professor, Pathology, Community Based Medical College Bangladesh, Mymensingh

4. Dr. Mst. Khurshida Jahan Department of Obstetrics \& Gyanecology. Mymensingh Medical College
Address of Correspondence Email: mmukkhan@gmail.com Mobile : +880 01711350724 
homosexuals, prostitutes, percutaneous drug abusers, persons taking acupuncture, tattooing, infants of HBV carrier mothers and patients who are immunocompromised 3,6.7.

It is interesting to note that the infection may spread through physical contact between children with skin conditions, such as impetigo and scabies or with cuts or grazes. Transmission by blood sucking arthropods may occur but there is no convincing report to support this view. However Hepatitis B viruses do not spread by holding or shaking hands, sharing dining table utensils, drinking glasses, kissing, hugging, coughing, sneezing or breast feeding 8,9 .

The acute illness causes liver inflammation, vomiting, jaundice, and rarely death. Chronic hepatitis B may eventually cause cirrhosis and liver cancer - a disease with poor response to all but a few current therapies ${ }^{10}$. Since there is no specific treatment, prevention has been the major aim in managing viral hepatitis $B$. The infection is preventable by vaccination ${ }^{11}$.

Hepatitis B virus is a hepadnavirus - hepa from hepatropic (affinity to the liver) and dna because it is a DNA virus ${ }^{12,13}$. It has a circular genome of partially double stranded DNA. Hepatitis B virus has three distinct antigens: a surface antigen ( $\mathrm{HBsAg})$, a core antigen $(\mathrm{HBcAg})$ and an 'e' antigen ( $\mathrm{HBeAg})$. They stimulate the production of corresponding antibodies. These antibodies and their antigens constitute very useful markers of HBV infection. Antibodies form in a week or two after the onset of jaundice - the order being, the first core antibody " $c$ ", then " $e$ " antibody and much later "s" surface antibody. The appearance of surface antibody signals recovery from HBV infection and the development of immunity 14,15 .

Since HBV infection is a global problem, with $66 \%$ of the entire world's population living in areas where there are high level of infection and reports so far available in Bangladesh evidence that the carrier rate is quite high, the present study was therefore undertaken to determine the distribution of the HBV infection by age, sex and social status among medical students admitted into a private medical college.

\section{Methods}

This is a descriptive type cross sectional study. The primary objective was to describe the occurrence and distribution of disease hepatitis $B$ in medical students and find out the health related events or characteristics within population. The persons who had the disease were defined by age, sex and social class factors.

The prevalence of the disease was estimated from the "cross sectional" studies. This was an observational study and was based on a single examination of a cross section of people (1643 medical students who got admitted at one point of Community Based Medical College, Mymensingh in time period from 1995 to 2012. Data were obtained from admission record of the individual student.

Every year selected students before admission needs to undergo medical check up. Physical and laboratory examination are done as per proforma. Of the laboratory examinations, blood group, Rh typing, HBsAg and HIV tests and chest X-ray are done. Further tests were done for confirmation in positive cases. In relation to HBV infection, the host factors, such as age, sex and social class of students associated with the development of the disease were considered. All data were analyzed using a Microsoft excel program.

\section{Results}

Among the 1643 medical students there were $05 \mathrm{HBsAg}$ positive cases of which one is male and the rest four students belonged to female sex group. The mean age estimated was 17.6 (SD \pm .812 ) years.

Table -1 Total number of student and their sex wise distribution.

\section{Table I}

Distribution of the patients by sex $(n=1643)$.

\begin{tabular}{|l|l|}
\hline Male & 954 \\
\hline Female & 689 \\
\hline Total & 1643 \\
\hline
\end{tabular}

The percentage of potential infection among students revealed $0.30 \%$. So the study 
showed that prevalence of some infectious diseases are less in educated and well offpopulation. This may be due to their better awareness.

Table 2 Percentage of population affected (HBs $\mathrm{Ag}+\mathrm{ve}$ ) and their sex wise distribution.

\begin{tabular}{|c|c|c|c|c|}
\hline $\begin{array}{c}\text { Total } \\
\text { populatio }\end{array}$ & $\begin{array}{c}\text { Affected } \\
\text { population }\end{array}$ & Percentage & Male & Female \\
\hline 1643 & 5 & $0.30 \%$ & 1 & 4 \\
\hline
\end{tabular}

\section{Discussion}

The present study is a descriptive type of cross sectional study. Study population are newly admitted 1st year MBBS student of a private Medical College of Bangladesh. It has provided information about the disease prevalence which is found to be only $0.30 \%$. This phenomenon demonstrates the percentage distribution and does not suggest causal hypothesis. Moreover the study provides little information about the natural history of HBV infection or the rate of occurrence of new cases. The variables sex and social class of persons who develop the disease were studied. Among 1643 admitted students only $05(0.30 \%)$ were affected, of which 01 male and 04 female and all are from middle and upper middle class family.

All students under this study program were from well-to-do socioeconomic class as we all know that study in private medical college in Bangladesh is expensive. Mean age of students $17.6(\mathrm{SD} \pm .812)$ years.

Evidencing the fact that HBV infection is generally low in population with high standard of living. Experts are of the opinion that in countries in which infection with HBV is relatively low, the highest prevalence is found in the years 20 to 40 year age group 15 .

Similar study was done among the students of Viqarunnessa noon girls school (Dhaka, Bangladesh) children in 1995. Among 836 students of age 6-15 years, 07 cases was found $\mathrm{HBsAg}$ positive means prevalence is $0.8 \%$. Comparison of these findings with studies conducted in other countries indicates that urban Bangladeshi children from high socioeconomic status backgrounds have significantly lower $\mathrm{HBsAg}$ prevalence than their counterparts in Egypt, India, Greece, Poland, Turkey, Saudi Arabia, Thailand, Tanzania, Senegal, Romania, and Cameroon (range, 5.0-23.2\%). The reason of this fact presumably was that in this study serum specimens were collected from apparently healthy female children belonging to high socioeconomic status in Bangladesh ${ }^{16}$.

The investigation of ICDDR'B researcher on 1997 person coming from different parts of Dhaka city found the prevalence and risk factors of hepatitis in urban areas of Bangladesh. The result indicated intermediate level of endemicity of HBV infection in Dhaka community, with much higher prevalence among family members of $\mathrm{HBsAg}$ positive individuals but low prevalence of $\mathrm{HCB}$ infections, clearly indicating the need for universal hepatitis $B$ vaccination. It has been advocated that the use of disposable needles for ear-nose-body piercing need to be promoted through public awareness programs as a preventive strategy ${ }^{17}$.

In an epidemiological study conducted in the Department of Hepatology of Bangabandhu Sheikh Mujib Medical University ( BSMMU) showed that out of 1016 samples $5.5 \%$ were found sero-positive. Hepatitis B virus (HBV) is encountered sporadically all the year round in Bangladesh. It results in a wide range of liver diseases with asymptomatic acute hepatitis at one end to hepatocellular carcinoma (HCC) at the other end of the spectrum ${ }^{18}$.

Spread of infection from HBV carrier mothers to their babies appears to be an important factor for the high prevalence of HBV infection in some regions, particularly China and SE Asia. The risk of infection varies from country to country and may reach $40 \%$. A survey was conducted by ICDDR'B in different rural areas of Bangladesh to find out the prevalence of $\mathrm{HBV}$ and perinatal transmission of HBV to the fetus. The result indicated that hepatitis $B$ is prevalent in Bangladesh at $5 \%$ and that the perinatal mode of transmission may be relatively low ${ }^{19}$. The mechanism of perinatal infection is uncertain. Researchers believe that HBV can infect the fetus in utero, but this 
rarely happens. Most infections appear to occur at birth, as a result of a leak of maternal blood into the baby's circulation, or ingestion or accidental inoculation of blood. Infection in baby is usually anicteric and is recognized by the appearance of surface antigen between 60 to 120 days after birth ${ }^{15}$.

From a number of studies it is evidenced that the prevalence of $\mathrm{HBV}$ in urban and rura areas of Bangladesh is more or less same, that is about $5.5 \%$. However in our present study on a population with good socioeconomic class the prevalence is much lower, which is $0.30 \%$. This is probably due to the high standard of living, awareness, education and understanding of vaccination. The present study focused on the preventive measures to be undertaken in this country; Firstly, all blood donors should be screened for HBV infection and positive reactors should be rejected. Secondly, we should encourage in voluntary blood donation and avoid purchase as in this blood there is a higher risk of infusion hepatitis. Thirdly, health care personnel, medical and dental practitioners need to sterilize adequately all instruments and maintain proper hygienic measures. Fourthly carriers should not donate blood and use the same razors or tooth brushes. Lastly, preexposure prophylaxis is indicated and hepatitis $B$ vaccine must be used in the same category as DPT and polio. Many developing countries are now using childhood vaccines in their national immunization program. Bangladesh included the HBV vaccine in their immunization program for the last few years. While vaccinating we should keep it in mind that the vaccine has no effect on the HBsAg carriers, and unnecessary, in persons with surface antibody from previous infection. It is very encouraging to note that "World Hepatitis Day" led by World hepatitis alliance has been observed recently - the aims are to raise global awareness of hepatitis B and hepatitis $\mathrm{C}$ and introduce preventive measures, proper diagnosis and appropriate treatment 20. Vaccination program against HBV in medical students is encouraging and done by Shandhani social club in Bangladesh.

\section{References}

1. Barker, LF et al (1996). Transmission of serum hepatitis 1970: J. Am. Med. Assoc. 276 (10), pp 841-844.

2. Williams, R. (2006). Global changes in liver diseases. Hepatology (Baltimore, Md.): 44(3): pp. 521-526.

3. "Hepatitis $B$ ". World Health Organization. Retrieved 2009-09-19FAQ

4. "FAQ about Hepatitis B". Stanford School of Medicine. 2008-07-10. Retrieved 2009-09-19

5. Coopstead, Lee-Ellen C. (2010). Pathophysiology. Missouri. 1st edition, 2010, Saunders. pp 886-887,

6. Sleisenger, $M H$, Feldman, $M$, Friedman LS (2006). Fordtran's gastrointestinal and liver disease: pathophysiology, diagnosis, management (8th edition), Philadelphia. Saunders, pp 215-218

7. Kidd-Ljunggren, $K$, Holmberg, A, Bläckberg, J, Lindqvist, $B$ (December 2006). High levels of hepatitis $B$ virus DNA in body fluids from chronic carriers. The journal of hospital infection 64(4): 352- 357,

8. "Hepatitis $B$ ". National Institute of health. Retrieved 2010-11-23

9. "Hepatitis B FAQ - Transmission". US centers for Disease Control and Prevention. Retrieved 2011;11-29

10. Chang, M. (2007) Hepatitis $B$ virus infection. Seminars in fetal and neonatal medicine 12(3): 160-167.

11. Pungpapong,S., Kim, W, Poterucha, J (2007). Natural History of Hepatitis $B$ virus Infection: an update for clinicians. Mayo clinic proceedings 82 (8): 967-975.

12. Zuckerman, AJ. Hepatitis viruses . In Baron, S. Et al Baron's Medical microbiology; 1996 :4th ed. University of Texas Medical publisher; pp 234-235.

13. Locarinini, $S$ (2004) Molecular virology of hepatitis $B$ virus. Seminar in liver disease 24 (suppl 1). 3 -10.

14. http://www.hepb.org/patients/hepatitis_b_ blood_tests.htm. 
15. Park, K (2000) Park's textbook of preventive and social medicine, 16 th ed., publisher M/S Banarsidas Bhanot 1167 Premnagar, jabalpur. 482.001, India, pp159-162

16. LashkarMS,HaradaN,KhanF, Prevalence of HepatitisB surface antigen in Viqarunnnesa noon girl's school children in Dhaka, Bangladesh; cent Eur J Public health,1997 Dec;5(4):202-4

17. Ashraf, H., Alam, NH, Rothermundt, C., Brooks, A, Bardhan, P, Hossain, L, Salam, MA, Hassan, MS, Beglinger, C, Gyr, N. (2010) Prevalence and risk factors of hepatitis $B$ and $C$ virus infection in an impoverished urban community in Dhaka, Bangladesh BMC Infect Dis. $2010 \mathrm{Jul}$ 15; 10: 208

18. Mahtab, MA, Rahman, S, Karim, MF, Khan, M, Foster, G, Solaiman, S, Afroz, S (2008). Epideiology of Hepatitis $B$ virus in Bangladeshi general population. Hepatobiliary Pancreat Dis. Int. 2008 Dec. 7 (6); 596-600

19. De Francisco A, Hall, AJ, Alam, N, Hawkes, S, Azim, T,(1999). Hepatitis $B$ infection in Bangladeshi mothers ans infants. Southeast Asian J. Trop. Med. Public health 1999 Jun. 30 (2): 296-298 